\title{
Efeito da pré-exposição de vias aéreas de ratos com enterotoxina estafilocócica do tipo B (SEB) sobre a inflamação alérgica pulmonar
}

\author{
Effect of the pre-exposition of rats' airways with \\ staphylococci enterotoxin type B (SEB) on \\ pulmonary allergic inflammation
}

\author{
Jorge Luiz da Silva Rezende', João Baptista Opitz Neto', \\ Ivani Aparecida de Sousa ${ }^{2}$, Edson Antunes ${ }^{3}$
}

Rezende JL da S, Optiz Neto JB, Sousa IA de, Antunes E. Efeito da pré-exposição de vias aéreas de ratos com enterotoxina estafilocócica do tipo $B$ (SEB) sobre a inflamação alérgica pulmonar. Rev Med (São Paulo). 2008 jan.-mar.;87(1):23-31.

\begin{abstract}
RESUMO: Introdução: As enterotoxinas estafilocócicas (SEs) são produzidas e excretadas por algumas cepas da bactéria Staphylococcus aureus. A asma é uma doença caracterizada por resposta inflamatória crônica das vias aéreas. A administração sistêmica de SEB em coelhos produz inflamação pulmonar caracterizada por infiltração de leucócitos, danos no endotélio e aumento de permeabilidade vascular. Materiais e Métodos: Ratos da linhagem Wistar foram submetidos a um protocolo em que foram sensibilizados com ovalbumina (OVA) e 14 dias após receberam uma instilação intranasal de PBS ou SEB ou LPS. Após 4 horas receberam nova instilação intranasal de PBS ou OVA e após 24 horas foram colhidos os lavados broncoalveolares (BAL), Foi realizada a contagem total e diferencial das células e os resultados foram submetidos à análise estatística. Resultados: Em animais que receberam SEB e OVA, o influxo neutrofílico foi maior que naqueles que receberam somente SEB ou OVA. Nos animais que receberam LPS, os níveis de TNF- $\alpha$ foram maiores em animais submetidos ao protocolo de inflamação alérgica por OVA. Conclusão: A administração prévia de SEB ou LPS promoveu um influxo de neutrófilos, mas não de eosinófilos. A SEB e o LPS parecem agir por mecanismos diferentes no influxo de neutrófilos.
\end{abstract}

DESCRITORES: Staphylococcus aureus/virologia. Asma/virologia. Asma/imunologia. Exposição ambiental. Infecções respiratórias/imunologia. Ratos Wistar. Hipersensibilidade respiratória/ fisiopatologia. Hipersensibilidade/imunologia.

Prêmio Oswaldo Cruz - XXVI COMU, 2007: Área Básica.

1. Acadêmico da Faculdade de Medicina de Jundiaí.

2. Prof ${ }^{a}$. Dra ${ }^{\mathrm{a}}$. da Disciplina de Biologia e Fisiologia, da Faculdade de Medicina de Jundiaí.

3. Prof. Dr. da Faculdade de Medicina de Jundiaí.

Endereço para correspondência: Rua Francisco Telles, 250. Vila Arens - Jundiaí, SP. CEP: 13202-550. Caixa Postal: 1295. e-mail: jorgefmj@yahoo.com.br 


\section{INTRODUÇÃO}

\section{Enterotoxinas estafilocócicas}

A $S$ enterotoxinas estafilocócicas (SEs) pertencem a uma família de proteínas neurotóxicas produzidas e excretadas por algumas cepas da bactéria grampositiva Staphylococcus aureus. Estas toxinas são responsáveis pela maioria das intoxicações alimentares em humanos, podendo causar várias alterações fisiopatológicas que podem levar ao choque e morte ${ }^{38}$.

Embora os(s) mecanismos(s) de ação in vivo destas toxinas ainda não tenham sido claramente elucidados ${ }^{3,4,34}$, as manifestações enteropatológicas destas toxinas parecem envolver a estimulação de neurônios do trato gastrintestinal, macrófagos e linfócitos ${ }^{34}$. Em humanos, vários estudos demonstraram que os efeitos fisiopatológicos das SEs e de outras toxinas bacterianas envolvem a liberação de prostaglandinas, histamina, serotonina e leucotrienos, além de citocinas entre as quais a interleucina-1 (IL-1), IL-2, IL-6, IL-8, TNF- $\alpha$, interferon- $\gamma($ INF- $\gamma$ ) e NO, produzidos por células como os mastócitos, macrófagos e linfócitos ${ }^{6,14,18,25,27,34,51}$.

A administração sistêmica da SEB em camundongos induz a liberação de vários mediadores pró-inflamatórios, incluindo o TNF- $\alpha$, IFN- $\gamma$, IL-1, IL-2, IL-6, IL-10 e o NO ${ }^{19,23,25,35}$. O NO parece exercer efeito protetor contra o choque tóxico induzido por estas toxinas em camundongos, visto que a administração prévia de L-NAME potencializa o choque letal produzido por estas toxinas ${ }^{19}$.

Em relação à estimulação de neurônios sensoriais pelas SEs, sugere-se que a SEA e a SEB induzem em camundongos inflamação do tipo neurogênica. Nestes animais, o tratamento com capsaicina (substância capaz de depletar as fibras C sensoriais do seu conteúdo de neuropeptídeos) é capaz de reduzir a infiltração peritoneal de neutrófilos causada por estas $\mathrm{SES}^{7,8,9}$. O edema inflamatório induzido pela SEB em camundongos envolve a formação local de cininas, a ativação direta de receptores vanilóides em neurônios sensoriais e a desgranulação de mastócitos ${ }^{30}$.

A migração peritoneal de neutrófilos induzida por SEA ou SEB é modulada, em parte, por macrófagos residentes ${ }^{8,9}$. Além disto, mais recentemente demonstrou-se que macrófagos de camundongos estimulados in vitro com SEA ou SEB liberam, nos sobrenadantes, componentes protéicos com atividade quimiotáxica in vivo e in vitro para neutrófilos ${ }^{11,12}$.

\section{Asma brônquica}

A asma é uma doença mundial de prevalência progressiva, responsável por grande parte dos altos gastos em saúde pública ${ }^{15,50}$. Esta doença é uma condição caracterizada por resposta inflamatória crônica das vias aéreas, que resulta em broncoespasmo devido à liberação de uma variedade de mediadores inflamatórios espasmogênicos, provenientes de macrófagos alveolares, mastócitos, eosinófilos, linfócitos e neutrófilos ${ }^{5,39,41,50}$. O desenvolvimento da asma envolve interações entre fatores externos e genéticos, e tem como características clínicas crises de dispnéia, tosse e sibilos. É uma doença episódica, alternando crises agudas com períodos assintomáticos ${ }^{49}$.

A asma pode ser dividida em dois principais tipos: asma intrínseca e extrínseca. A asma intrínseca apresenta história negativa para alergia e níveis séricos normais de IgE. Neste caso, os pacientes desenvolvem os sintomas típicos de asma (sibilo e dispnéia) após a exposição das vias aéreas com certos estímulos tais como infecções virais e/ou bacterianas, ar frio, inalantes irritantes (ex: dióxido de enxofre), drogas (ex: aspirina), estresse emocional e exercício físico ${ }^{37,48}$. A asma extrínseca é caracterizada por uma reação de hipersensibilidade do tipo I induzida por um antígeno extrínseco. Este tipo inclui a asma alérgica (atópica), ocupacional e aspergilose broncopulmonar alérgica (colonização brônquica com Aspergillus, seguida pelo desenvolvimento de anticorpos $\lg \mathrm{E})^{37,48}$. A asma alérgica é a mais comum, sendo desencadeada por antígenos ambientais presentes na poeira, pólen, pêlos de animais, determinados alimentos, dentre outros. É freqüentemente associada a histórico familiar de atopia. As crises agudas podem ser precedidas por manifestações de doenças alérgicas, como rinite, urticária ou eczema, reações cutâneas positivas à injeção intradérmica de extratos de antígenos inalados, níveis elevados de lgE no soro, e/ou respostas positivas a testes de provocação, os quais envolvem a inalação de antígeno específico ${ }^{37,48}$.

Dados obtidos de pacientes asmáticos e de modelos experimentais de asma mostram que os eosinófilos desempenham papel importante nesta patologia, onde o acúmulo seletivo destas células e sua ativação na mucosa brônquica são considerados eventos centrais na patogênese da asma ${ }^{47}$. Pacientes asmáticos apresentam número elevado de eosinófilos no sangue e no lavado broncoalveolar, e infiltrado inflamatório pulmonar rico em células ativadas, como mastócitos, monócitos, linfócitos e, principalmente, eosinófilos $^{36,46}$. A importância dos eosinófilos na asma tem sido enfatizada pelos achados que correlacionam o grau de eosinofilia no sangue (e no 
lavado broncoalveolar) com o grau de hiperreatividade brônquica e a gravidade da doença ${ }^{24,46}$.

Eosinófilos ativados liberam substâncias citotóxicas, como radicais de oxigênio e proteínas tóxicas (proteína básica principal, proteína catiônica do eosinófilo e peroxidase do eosinófilo), além de produzirem e liberarem mediadores próinflamatórios, incluindo citocinas, quimiocinas e mediadores lipídicos que podem intensificar a resposta inflamatória ${ }^{20,22,43}$.

O recrutamento de eosinófilos para o tecido inflamado é um processo complexo, sendo regulado por vários fatores, incluindo citocinas, quimiocinas, NO e moléculas de adesão. Eosinófilos de pacientes alérgicos e asmáticos apresentam migração, adesão e desgranulação aumentadas em relação a eosinófilos de indivíduos sadios devido aos níveis circulantes aumentados de IL-3, IL-5 e fator estimulador do crescimento de granulócitos e monócitos (GMCSF). Sendo assim, a exposição dos eosinófilos a determinadas citocinas modifica o fenótipo destas células tornando-as "primadas" (ativadas), caracterizando assim a etapa de priming ${ }^{29}$.

Várias espécies animais têm sido usadas em modelos experimentais de asma, incluindo cobaia, cão, camundongos e ratos ${ }^{21,31,32,33,41,42}$. Entretanto, devido à complexidade da doença, a asma não tem sido totalmente reproduzida em animais, existindo apenas modelos de inflamação alérgica que reproduzem algumas características da doença, como broncoconstrição, hipersecreção de muco e inflamação crônica com infiltração de leucócitos ${ }^{49}$. O procedimento experimental mais frequentemente utilizado é a indução de um estado alérgico, que é caracterizado por uma hipersensibilidade do tipo imediata ou anafilática a um antígeno conhecido. Isto pode ser obtido através da sensibilização à ovalbumina, normalmente associada ao hidróxido de alumínio, que resulta em imunidade mediada por células e formação de anticorpos (principalmente a $\lg \mathrm{E}$ ), dependente de células $\mathrm{T}$ (no caso, células $\mathrm{TH}_{2}$ ). Após 14 dias da sensibilização, a resposta inflamatória alérgica pode ser observada nos animais após a provocação intranasal ou intratraqueal com o alérgeno ${ }^{16,17,28,42,44}$.

Resposta inflamatória pulmonar produzida por enterotoxinas estafilocócicas

Em coelhos, a administração sistêmica de SEB produz inflamação pulmonar caracterizada por infiltração de leucócitos, danos no endotélio e aumento de permeabilidade vascula ${ }^{40}$. Além disto, uma resposta inflamatória pulmonar caracterizada por influxo de linfócitos, eosinófilos e neutrófilos também foi observada após a administração intranasal de SEB em camundongos ${ }^{26}$. Resultados recentes em nosso laboratório mostraram que a administração intratraqueal de SEA em ratos induz resposta inflamatória pulmonar caracterizada por influxo predominante de neutrófilos, cuja resposta máxima é observada $4 \mathrm{~h}$ após a administração de SEA ${ }^{13}$. Baseados no fato de que tanto a SEA como a SEB foram incapazes de induzir quimiotaxia ou adesão de neutrófilos in vitro, passamos então a investigar, através da utilização de antagonistas e inibidores farmacológicos, quais seriam os possíveis mediadores envolvidos na resposta inflamatória pulmonar induzida por estas SEs. Estes resultados revelaram que tanto a SEA como a SEB induzem uma resposta inflamatória dependente de mediadores como metabólicos da ciclooxigenase-2, da lipoxigenase e do NO. Estes resultados foram confirmados pelo aumento de expressão de RNAm para COX-2 e para iNOS observado em tecido pulmonar de ratos estimulados com SEA, e pelo efeito do pré-tratamento dos animais com antagonistas específicos para COX-2 e iNOS no caso da SEB, além dos níveis aumentados de $\mathrm{PGE}_{2}$ e $\mathrm{LTB}_{4}$ no lavado broncoalveolar de animais expostos à SEA ou SEB ${ }^{13}$. Além destes mediadores,os níveis de citocinas como TNF- $\alpha$, IL-6 e IL-10 também se encontram aumentados no lavado broncoalveolar de ratos submetidos á exposição aérea com SEA ou SEB.

\section{OBJETIVOS GERAIS}

O principal objetivo deste trabalho é investigar uma possível exacerbação da resposta inflamatória pulmonar alérgica em ratos pré-expostos a SEB, procurando investigar os principais mediadores e/ou citocinas envolvidas no influxo celular para o lavado broncoalveolar destes animais.

\section{OBJETIVOS ESPECÍFICOS}

O objetivo desta etapa do trabalho foi investigar o efeito de várias doses de SEB em induzir exacerbação da resposta inflamatória alérgica induzida por Ovalbumina.

\section{MATERIAIS E MÉTODOS}

\section{Animais}

Foram utilizados ratos machos da linhagem Wistar, pesando 200-250 g, provenientes do Centro de Bioterismo da UNICAMP. Os animais foram mantidos a $24^{\circ} \mathrm{C}$, com iluminação diária de $12 \mathrm{~h}$ e com água e alimentação ad libitum. 
Rezende JL da S et al. Efeito da pré-exposição de vias aéreas de ratos. (OVA)

Sensibilização dos animais com ovalbumina

Os animais foram sensibilizados através da injeção subcutânea no dorso $(0.15 \mathrm{ml})$ de uma solução contendo $200 \mu \mathrm{g}$ de ovalbumina (OVAgrau III, Sigma) adsorvida em $8 \mathrm{mg}$ de hidróxido de alumínio, preparada em solução fisiológica. Estes animais foram utilizados para os protocolos experimentais quatorze dias após a sensibilização com OVA.

Pré-exposição de animais sensibilizados ao LPS ou SEB

Quatorze dias após a sensibilização, os animais foram divididos em 2 grupos (contendo 10 animais em cada grupo) que foram anestesiados pela via inalatória com halotano e submetidos à instilação intranasal com os seguintes estímulos: 1) Grupo 1: 0,2 $\mathrm{ml}$ de solução fisiológica tamponada estéril (PBS); 2) Grupo 2: 0,2 ml de solução de LPS ou SEB em diferentes doses. O desafio antigênico com OVA foi realizado 4 h após a pré-exposição dos animais com PBS, LPS ou SEB. Para isto, os animais (divididos em 4 grupos contendo 5 animais em cada) foram novamente anestesiados pela via inalatória com halotano e receberam uma nova instilação intranasal com os seguintes estímulos: 1) Grupo 1: $0,2 \mathrm{ml}$ de solução de PBS (grupo previamente exposto ao PBS); 2) Grupo 2: 0,2 ml de solução de OVA na concentração de $5 \mathrm{mg} / \mathrm{ml}$ (grupo previamente exposto ao PBS); 3) Grupo 3: 0,2 ml de solução de PBS (grupo previamente exposto ao LPS ou SEB); 4) Grupo 4: $0,2 \mathrm{ml}$ de solução de OVA na concentração de $5 \mathrm{mg} / \mathrm{ml}$ (grupo previamente exposto a LPS ou SEB). O lavado broncoalveolar destes animais foi obtido 12 e $24 \mathrm{~h}$ após a segunda instilação intranasal dos estímulos.

\section{Obtenção do lavado broncoalveolar (BAL)}

Os lavados broncoalveolares (BAL) foram obtidos $24 \mathrm{~h}$ após a segunda administração dos estímulos. Para isto, os animais foram sacrificados e a região do pescoço aberta para canulação da traquéia com auxílio de um tubo de polietileno (1 mm de diâmetro). O BAL foi realizado com 25 $\mathrm{ml}$ de tampão PBS contendo $20 \mathrm{Ul} / \mathrm{ml}$ de heparina e enriquecido com albumina bovina $(0,03 \%)$, à temperatura ambiente. O PBS foi injetado e cuidadosamente aspirado em 4 alíquotas, sendo a primeira de $10 \mathrm{ml}$ e as demais de $5 \mathrm{ml}$. O material recolhido foi centrifugado a $1000 \mathrm{~g}$, por 10 minutos à $20^{\circ} \mathrm{C}$, e o resíduo celular ressuspenso em PBS. A contagem do número total de leucócitos foi realizada em câmara de Neubauer e a contagem diferencial de leucócitos realizada em lâminas confeccionadas em citocentrífuga e coradas a seguir com corante May-Grünwalds. A leitura das lâminas foi realizada em microscópio óptico com aumento de 1000 vezes (objetiva de imersão em óleo). Em cada lâmina, foram contadas 200 células, diferenciando 4 tipos celulares: neutrófilos, eosinófilos, mononucleares e mastócitos. O número de cada tipo celular foi calculado a partir da porcentagem encontrada, em relação ao número total de células. Os resultados das contagens total e diferencial dos leucócitos foram expressos como número de célula por ml de lavado broncoalveolar.

\section{Análise estatística}

Os resultados obtidos serão expressos como média \pm erro padrão das médias (E.P.M.). Diferenças estatísticas serão determinadas por análise de variância (ANOVA) seguida pelo teste de Bonferroni para comparações múltiplas. Valores de $p<0,05$ serão considerados significativos.

\section{RESULTADOS}

Os dados apresentados na Tabela 1 mostram que tanto a SEB quanto a OVA induzem, 12h após, um significativo influxo neutrofílico para o BAL em comparação aos resultados obtidos em animais que receberam apenas PBS como estímulo (Grupo Controle). Estes resultados revelam ainda que em animais que receberam SEB e $4 \mathrm{~h}$ após OVA, a migração de neutrófilos foi significativamente maior do que aquela observada em animais que receberam apenas SEB ou apenas OVA como estímulo intranasal. Neste estudo realizamos vários protocolos experimentais onde utilizamos diferentes doses de SEB. Conforme pode ser observado na Tabela 1, a dose de SEB mais eficaz em induzir exacerbação da migração de neutrófilos provocada pela OVA foi a dose de $0,3 \mu \mathrm{g}$.

Os dados ilustrados na Tabela 2 mostram que os níveis de TNF- $\alpha$ são significativamente maiores em animais submetidos ao protocolo de inflamação alérgica por OVA, que foram previamente expostos à administração intranasal de LPS. No entanto os níveis de TNF- $\alpha$ não foram significativamente maiores no BAL de animais previamente expostos ao SEB do que aqueles expostos a PBS. Além disto, em animais previamente expostos a SEB encontramos níveis elevados de IL-10. 
Tabela 1. Efeito da pré-exposição das vias aéreas com SEB sobre a exacerbação do influxo de neutrófilos para o lavado broncoalveolar de ratos submetidos à inflamação alérgica por OVA

\begin{tabular}{lc}
\hline Tratamento & Neutrófilos $/ \mathrm{ml}\left(\times \mathbf{1 0}^{6}\right)$ \\
\hline PBS $-4 \mathrm{~h}$ após -PBS & $0,05 \pm 0,01$ \\
PBS $-4 \mathrm{~h}$ após -OVA & $0,42 \pm 0,16$ \\
SEB $(0,1 \mu \mathrm{g})-4 \mathrm{~h}$ após -PBS & $0,18 \pm 0,04$ \\
SEB $(0,1 \mu \mathrm{g})-4 \mathrm{~h}$ após -OVA & $3,55 \pm 0,52^{*}$ \\
SEB $(0,3 \mu \mathrm{g})-4 \mathrm{~h}$ após -PBS & $0,56 \pm 0,12$ \\
SEB $(0,3 \mu \mathrm{g})-4 \mathrm{~h}$ após -OVA & $4,78 \pm 1,23^{*}$ \\
SEB $(1 \mu \mathrm{g})-4 \mathrm{~h}$ após -PBS & $0,28 \pm 0,05$ \\
SEB $(1 \mu \mathrm{g})-4 \mathrm{~h}$ após -OVA & $1,85 \pm 0,52^{*}$ \\
\hline
\end{tabular}

${ }^{*} p<0,05$ comparado com o grupo que recebeu PBS e SEB.

O lavado broncoalveolar foi obtido $12 \mathrm{~h}$ após a administração intranasal de PBS e OVA, conforme o esquema descrito no item Materiais e Métodos. Os resultados estão expressos como média \pm EPM de 5-6 animais.
Tabela 2. Efeito da pré-exposição das vias aéreas com SEB ou com LPS sobre os níveis de TNF- $\alpha$ ou de IL-10 no lavado broncoalveolar de ratos submetidos à inflamação alérgica por OVA

\begin{tabular}{lcl}
\hline Tratamento & $\begin{array}{c}\text { TNF }-\mathbf{A} \\
\text { (PG/ML) }\end{array}$ & $\begin{array}{l}\text { IL-10 } \\
\text { (PG/ml) }\end{array}$ \\
\hline PBS $-4 \mathrm{~h}$ após -PBS & $4,23 \pm 0,5$ & $24,01 \pm 0,6$ \\
PBS $-4 \mathrm{~h}$ após -OVA & $41,55 \pm 12,5$ & $34,5 \pm 5,1$ \\
SEB $(1 \mu \mathrm{g})-4 \mathrm{~h}$ após -PBS & $39,39 \pm 7,68$ & nd \\
SEB $(1 \mu \mathrm{g})-4 \mathrm{~h}$ após -OVA & $33,65 \pm 16,1$ & $65,6 \pm 7,6$ \\
LPS $(1 \mu \mathrm{g})-4 \mathrm{~h}$ após -PBS & $10,96 \pm 0,64$ & nd \\
LPS $(1 \mu \mathrm{g})-4 \mathrm{~h}$ após -OVA & $40,77 \pm 18,8$ nd \\
\hline
\end{tabular}

${ }^{*} p<0,05$ comparado com o grupo que recebeu PBS e SEB.

O lavado broncoalveolar foi obtido $12 \mathrm{~h}$ após a administração intranasal de PBS e OVA, conforme o esquema descrito no item Materiais e Métodos. $O$ lavado broncoalveolar foi submetido a dosagem das citocinas acima por kits de Elisa de acordo com as instruções do fabricante. Os resultados estão expressos como média \pm EPM de 5-6 animais.

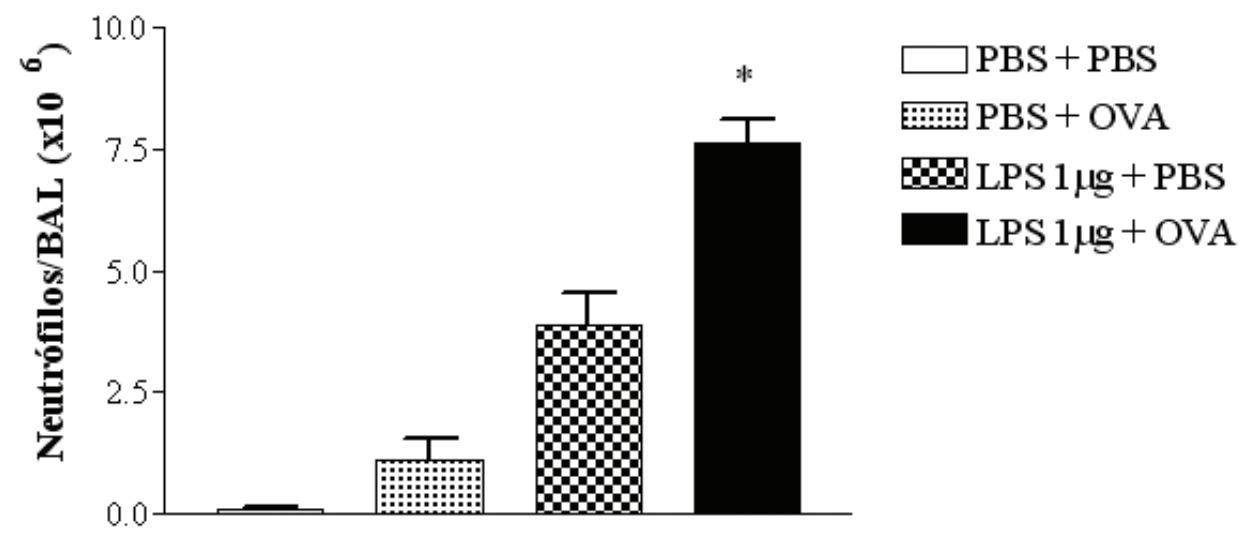

Figura 1. Efeito da pré-exposição das vias aéreas com LPS $(1 \mu \mathrm{g})$ sobre a exacerbação do influxo neutrófilos para o lavado broncoalveolar de ratos submetidos à inflamação alérgica por OVA. O lavado broncoalveolar foi obtido $24 \mathrm{~h}$ após a administração intranasal de PBS e OVA, conforme o esquema descrito no item Materiais e Métodos. Os resultados estão expressos como média \pm EPM de 5-6 animais. * $p<0,05$ comparado com o grupo que recebeu PBS e LPS.

\section{DISCUSSÃO}

A inflamação aguda pulmonar é um importante componente de doenças alérgicas das vias respiratórias, tais como asma brônquica associada com edema, infiltração de leucócitos (eosinófilos, principalmente) e liberação de vários mediadores inflamatórios. Além disto, vários estudos têm demonstrado uma correlação entre o desenvolvimento de asma brônquica não alérgica, sem a presença de eosinófilos, e infecções bacterianas ${ }^{15}$. Resultados recentes em nosso laboratório têm demonstrado que tanto a SEA como a SEB são capazes de induzir uma resposta inflamatória pulmonar em ratos, caracterizada por influxo predominante de neutrófilos. O influxo neutrofílico para o lavado broncoalveolar de ratos foi máximo $4 \mathrm{~h}$ após a administração de ambas as toxinas, e foi acompanhado por aumento destas células no sangue circulante e por um aumento de neutrófilos imaturos na medula óssea destes animais $16 \mathrm{~h}$ após o estímulo com SEs. O influxo predominante de neutrófilos para o BAL produzido tanto pela SEA como pela SEB nos levou a sugerir que estas toxinas induzem uma asma brônquica não alérgica, sem a presença de eosinófilos ${ }^{13}$.

Nossos resultados têm demonstrado que a 
Rezende JL da S et al. Efeito da pré-exposição de vias aéreas de ratos.

administração intranasal prévia de SEB aumenta o influxo neutrofílico provocado pela OVA $12 \mathrm{~h}$ após. Estes resultados estão de acordo com dados da literatura que revelam a existência de uma forte correlação entre a infecção das vias aéreas por Staphylococcus aureus e conseqüente secreção de enterotoxinas e a exacerbação de doenças do trato respiratório tais como a asma brônquica ${ }^{1,2,45}$.

Com o intuito de investigar se este fenômeno é comum a todo e qualquer produto bacteriano, realizamos, nesta etapa do trabalho, alguns protocolos experimentais onde o LPS, um lipopolissacarídeo bacteriano, foi utilizado como estímulo prévio a injeção intranasal de OVA, ao invés de SEB.

Nossos resultados demonstraram que somente a dose de $1 \mu \mathrm{g}$ de LPS foi capaz de promover um aumento no número de neutrófilos no BAL de animais estimulados com OVA. Embora estes resultados tenham sido estatisticamente significativos, é importante ressaltar que o aumento de neutrófilos, observado no grupo de animais que foi previamente exposto à dose de $1 \mu \mathrm{g}$ de LPS e a seguir recebeu OVA, pode representar uma soma do influxo de neutrófilos provocado pela OVA ou pelo LPS isoladamente e não necessariamente uma potencialização do efeito da OVA, conforme o que foi observado para a SEB.

Pacientes portadores de asma alérgica apresentam número elevado de eosinófilos no sangue e no lavado broncoalveolar (BAL ${ }^{46}$, e infiltrado inflamatório pulmonar rico em células ativadas, como mastócitos, monócitos, linfócitos e, principalmente, eosinófilos ${ }^{5}$. A importância dos eosinófilos na asma tem sido enfatizada pelos achados que correlacionam o grau de eosinofilia no sangue (e BAL) com o grau de hiperreatividade brônquica e severidade da doença ${ }^{24,46}$. Eosinófilos ativados liberam substâncias citotóxicas, como radicais de oxigênio e proteínas tóxicas (proteína básica principal, proteína catiônica do eosinófilo e peroxidase do eosinófilo), além de produzirem e liberarem vários mediadores pró-inflamatórios, incluindo citocinas, quimiocinas e mediadores lipídicos, que podem intensificar a resposta inflamatória ${ }^{20,22,43}$.

Os inúmeros achados obtidos de pacientes asmáticos e de modelos experimentais de asma demonstram que os eosinófilos desempenham papel importante nesta patologia. Seu acúmulo seletivo e ativação na mucosa brônquica são considerados o evento central na patogênese da asma ${ }^{47}$.

Vários modelos experimentais de asma têm sido estudados, dentre eles estão incluídos a cobaia, o cão e o camundongo ${ }^{21,31,41,42,44}$. Entretanto, é importante saber que apesar de utilizarmos o termo "modelo de asma", não existe um modelo ideal de asma. Devido à complexidade da doença, ela não pode ser totalmente reproduzida em nenhum animal. Na realidade, o que existe são modelos de inflamação alérgica que reproduzem algumas características da doença ${ }^{49}$. Em todos estes modelos, o objetivo é induzir nos animais algumas das manifestações fisiopatológicas da asma humana, tais como: broncoconstrição com aumento da resistência das vias aéreas, hipersecreção de muco, inflamação crônica com infiltração de eosinófilos, e hiperreatividade a agentes broncoconstritores. Para atingir o objetivo proposto, os animais são expostos a vários agentes, entre os quais o modelo de inflamação alérgica utilizado neste trabalho, onde os animais são previamente sensibilizados com OVA e 14 dias após recebem um desafio antigênico com OVA. É necessário esclarecer ainda que, em nossos protocolos experimentais iniciais, os animais foram submetidos a uma instilação, prévia a OVA, com SEB, com o intuito de verificar se haveria uma exacerbação da eosinofilia provocada pela OVA, fator este que diante do exposto acima é característico de uma asma alérgica. No entanto, nossos dados revelaram que a administração prévia de SEB foi capaz apenas de promover um aumento no infiltrado de neutrófilos em animais sensibilizados e desafiados com OVA, mas não interferiu com o influxo de eosinófilos que seria maior indicativo de inflamação pulmonar alérgica. A ausência de exacerbação no número de eosinófilos também foi observada nos protocolos experimentais onde a SEB foi substituída por LPS. Analisando o conjunto de dados obtidos, poderíamos sugerir ainda que, embora tenhamos observado o mesmo perfil de exacerbação no número de neutrófilos e ausência de exacerbação no influxo de eosinófilos com a dose de $1 \mu \mathrm{g}$ de LPS, a SEB parece ser mais potente do que o LPS em induzir tal efeito.

Porém, o mecanismo pelo qual o LPS e a SEB induzem exacerbação do influxo de neutrófilos parece envolver liberação de citocinas tais como o TNF- $\alpha$ e IL10. No entanto, apenas os grupos que receberam LPS como estímulo prévio a OVA tiveram níveis significativamente aumentados de TNF- $\alpha$, o que sugere que SEB e LPS possuem mecanismos de ação diferentes em induzir exacerbação do influxo de neutrófilos provocado pela OVA. Outra citocina, que tem sido descrita por suas propriedades antiinflamatórias, tem seus níveis aumentados no BAL de animais que foram previamente tratados com SEB. Estes dados revelam que SEB e LPS representam produtos bacterianos capazes de exacerbar o influxo de neutrófilos para o pulmão de ratos submetidos a inflamação alérgica por OVA. Estes dados contribuem para compreender recentes achados na literatura mostrando que indivíduos portadores de anticorpos para enterotoxinas estafilocócicas são mais susceptíveis a desenvolver asma, e representam novas perspectivas experimentais para explicar o mecanismo pelo qual estas toxinas apresentam tais efeitos. 
Rezende JL da S, Optiz Neto JB, Sousa IA de, Antunes E. Effect of the pre-exposition of rats' airways with staphylococci enterotoxin type B (SEB) on pulmonary allergic inflammation. Rev Med (São Paulo). 2008 jan.-mar.;87(1):23-31.

\begin{abstract}
S: Introduction: The staphylococci enterotoxin (SEs) are produced and secreted by some kind of Staphylococcus aureus. The asthma is a disease characterized by a chronic inflammatory response of the airways. The systemic administration of SEB in rabbits causes a pulmonary inflammation characterized by leukocytes infiltration, endothelium damage and increase of vascular permeability. Materials and Methods: Rats were submitted to a protocol that they were sensitized with ovalbumin (OVA) and after 14 days they received a nasal instillation of PBS or SEB or LPS. After 4 hours the rats received a new nasal instillation of PBS or OVA and after 24 hours the bronchoalveolar lavage (BAL) were obtained. The total and differential count was done and the results were submitted to a statistical analysis. Results: The neutrophil influx was larger in those animals that received SEB and OVA than those animals that received only SEB or only OVA. In those animals that received LPS, the levels of TNF- $\alpha$ were larger in animals submitted to the protocol of allergic inflammation caused by OVA. Conclusion: The pre-administration of SEB or LPS promoted a neutrophil influx, but not an eosinophil influx. SEB and LPS seems to act of different mechanism in the neutrophil influx.
\end{abstract}

KEY WORDS: Staphylococcus aureus/virology. Asthma/virology. Asthma/immunology. Environmental exposure. Respiratory tract infections/immunology. Rats, Wistar.

\title{
REFERÊNCIAS
}

1. Bachert C, Gevaert P, Van Cauwenberge P. Staphylococcus aureus superantigens and airway disease. Curr Allergy Asthma Rep. 2003;2:252-8.

2. Balaban N, Rasooly A. Staphylococcal enteroxins. Int J Food Microbiol. 200;61:1-10.

3. Bergdoll MS, Chesney PJ, editors. Toxic shock syndrome. CRC Press; 1991. p. 51-73.

4. Bobak DA, Guerrant RL. New developments in enteric bacterial toxins. Adv Pharmacol. 1992;23:85-101.

5. Corrigan CJ, Kay AB. T cells and eosinophils in the pathogenesis of asthma. Immunol Today. 1992;13:501-6.

6. Cunha FQ, Poole S, Lorenzetti BB, Ferreira SH. The pivotal role of tumor necrosis factor $\alpha$ in the development of inflammatory hyperalgesia. $\mathrm{Br} \mathrm{J}$ Pharmacol. 1992;107:660-4.

7. DeSouza IA, Ribeiro-DaSilva G. Neutrophil migration induced by staphylococcal enterotoxin type $A$ in mice: a pharmacological analysis. Eur J Pharmacol. 1998;363:189-95.

8. DeSouza IA, Ribeiro-DaSilva G. Resident macrophages modulate the neutrophil migration induced by staphylococcal enterotoxin B into mouse peritoneal cavity. J Nat Toxins. 1996;5:341-50.

9. DeSouza IA, Ribeiro-DaSilva G. The pharmacological profile of mouse hind paw inflammation induced by staphylococcal enterotoxin type A. Inflamm Res. 1997;46:361-5.

10. DeSouza IA, Ribeiro-DaSilva G. Neutrophil migration induced by staphylococcal enterotoxin type $A$ in mice: a pharmacological analysis. Eur J Pharmacol. 1998;363:189-95.

11. DeSouza IA, Hyslop S, Franco-Penteado CF, Ribeiro-DaSilva G. Mouse macrophages release a neutrophil chemotactic mediator following stimulation by staphylococcal enterotoxin type A. Inflam Res. 2001;50:206-12.

12. DeSouza IA, Hyslop S, Franco-Penteado CF, Ribeiro-DaSilva G. Evidence for the involvement of a macrophage-derived chemotactic mediator in the neutrophil recruitment induced by staphylococcal enterotoxin B in mice. Toxicon. 2002;40:1709-17.

13. DeSouza IA, Franco-Penteado CF, Camargo EAP, Lima CSP, Teixeira SA, Muscará MN, et al. Inflammatory mechanisms underlying the rat pulmonary neutrophil influx induced by airway exposure to staphylococcal enterotoxin type A. Brit J Pharmacol. 2005;146:78191.

14. Dinarello CA. The proinflammatory cytokines interleukin-1 and tumor necrosis factor and treatment of septic shock syndrome. J Infect Dis. 1991;163:117784.

15. Douwes J, Gibson P, Pekkanen J, Pearce N. Noneosinophilic asthma: importance and possible mechanisms. Thorax. 2002;57:643-8.

16. Egan RW, Athwahl D, Chou CC, Emtage S, Jehn C-H, Kung TT, et al. Inhibition of pulmonary eosinophilia and hyperreactivity by antibodies to interleukin-5. Int Arch Allergy Immunol. 1995;107:321-2.

17. Ferreira HHA, Costa RAO, Jacheta JM, Martins AR, Medeiros MV, Macedo-Soares MF, et al. Modulation of eosinophil migration from bone marrow to lungs of allergic rats by nitric oxide. Biochem Pharmacol. 2004;68:631-9.

18. Ferreira SH. The role of interleukins and nitric oxide in the mediation of inflammatory pain and its control by peripheral analgesics. Drugs. 1993;46:1-9.

19. Florquin S, Amraoui Z, Dubois C, Decuyper J, Goldman 
M. The protective role of endogenously synthesized nitric oxide in staphylococcal enterotoxin B-induced shock in mice. J Exp Med. 1994;180:1153-8.

20. Foster PS. STAT6: an intracellular target for the inhibition of allergic disease. Clin Exp Allergy. 1999;29:12-6.

21. Gaspar Elsas MI, Joseph D, Xavier Elsas P, Vargaftig BB. Rapid increase in bone marrow eosinophil production and responses to eosinopoietic interleukins triggered by intranasal allergen challenge. Am J Resp Cell Mol Biol. 1997; 17:404-13.

22. Giembycz MA, Lindsay MA. Pharmacology of the eosinophil. Pharm Rev. 1999;51:213-339.

23. Gonzalo JA, Baixeras E, Gonzáles-Garcia A, GeorgeChandy A, Van Rooijen N, Martínez AC. Differential in vivo effects of superantigen and an antibody targeted to the same $T$ cell receptor: activation-induced cell death vs passive macrophage-dependent deletion. J Immunol. 1994;152:1597-608.

24. Gonzalo JA, Lloyd CM, Wen D, Albar JP, Wells TNC, Proudfoot A, et al. The coordinated action of CC chemokines in the lung orchestrates allergic inflammation and airway hyperresponsiveness. J Exp Med. 1998;188:157-67.

25. Haskó G. Virág L, Egnaczyk G, Salzman AL, Szabó C. The crucial role of IL-10 in the suppression of the immunological response in mice exposed to staphylococcal enterotoxin B. Eur J Immunol. 1998;28:1417-25.

26. Herz U, Rückert R, Wollenhaupt K, Tschernig T, Neuhaus-Steinmetz U, Pabst R, Renz H. Airway exposure to bacterial superantigen (SEB) induces lymphocyte-dependent airway inflammation associated with increased airway responsiveness - a model for non-allergic asthma. Eur J Pharmacol. 1999;29:102131.

27. Kluger MJ. Fever, role of pyrogens and cryogens. Physiol Rev. 1991;71:93-127.

28. Kung TT, Stelts D, Zurcher JA, Watnick AS, Jones $H$, Mauser $\mathrm{PJ}$, et al. Mechanisms of allergic pulmonary eosinophilia in the mouse. J Allergy Clin Immunol. 1994;94:1217-24.

29. Lampinen M, Carlson M, Hakansson LD, Venge P. Cytokine-regulated accumulation of eosinophils in inflammatory disease. Allergy. 2004;59:793-805.

30. Linardi A, Costa SKP, DaSilva GR, Antunes A. Involvement of kinins, mast cells and sensory neurons on the plasma exudation and paw oedema induced by staphylococcal enterotoxin B in the mouse. Eur $\mathrm{J}$ Pharmacol. 2000;399:235-42.

31. Lintomen L, Gaspar Elsas MIC, Maximiano ES, Paula Neto HA, Joseph D, Vargaftig BB, et al. Allergic sensitization prevents upregulation of haemopoiesis by cyclo-oxygenase inhibitors in mice. Br J Pharmacol. 2002;135:1315-23.

32. Medeiros MV, Macedo-Soares MF, De Luca IMS, Hyslop S, De Nucci G, Antunes E. Contribution of C-fibres to leucocyte recruitment in bronchoalveolar lavage fluid and pleural cavity in rat. Eur J Pharmacol. 2001;421:133-40.

33. Medeiros MV, De Luca IMS, Bricola AAO, Zanesco A, De
Nucci G, Antunes E. Enhanced airways responsiveness in rats depleted of sensory neuropeptides by neonatal capsaicin treatment. Neurosci Lett. 2003;341:103-6.

34. Micusan VV, Thibodeau J. Superantigens of microbiol origin. Semin Immunol. 1993;5:3-11.

35. Miethke T, Wahl C, Heeg K, Echtenacher B, Krammer $\mathrm{PH}$, Wagner $\mathrm{H}$. T cell-mediated lethal shock triggered in mice by superantigen staphylococcal enterotoxin $\mathrm{B}$ : critical role of tumor necrosis factor. J Exp Med. 1992;175:91-8.

36. Miller M, Sung KLP, Muller WA, Cho JY, Roman M, Castaneda D, et al. Eosinophil tissue recruitment to sites of allergic inflammation in the lung is platelet endothelial cell adhesion molecule independent. J Immunol. 2001;67:2292-7.

37. Miller AL. The etiologies, pathophysiology, and alternative/complementary treatment of asthma. Altern Med Rev. 2001;6:20-47.

38. Müller-Alouf H, Varnoy C, Simonet M, Alouf JE. Superantigen bacterial toxins: state of the art. Toxicon. 2001;39:1691-1701.

39. Negreiros B, Ungier C. Alergologia Clínica. São Paulo: Atheneu; 1995.

40. Neumann B, Engelhardt B, Wagner H, Holzamann $B$. Induction of acute inflammatory lung injury by staphylococcal enterotoxin B. J Immunol. 1997;158:1862-8.

41. O'Byrne PM, Gauvreau GM, Wood LJ. Interaction between haemopoietic regulation and airway inflammation. Clin Exp Allergy. 1999;29 Suppl. 2:2732.

42. Petrolani M, Lefort J, Vargaftig BB. Active immunization induces lung hyperresponsiveness in the guinea pig. Pharmacologic modulation and triggering role of the booster injection. Am Rev Respir Dis. 1988;138:1572-8.

43. Powell WS, Ahmed S, Gravel S, Rokach J. Eotaxin and RANTES enhance 5- oxo-6,8,11,14-eicosatetraenoic acid-induced eosinophil chemotaxis. J Allergy Clin Immunol. 2001;107:272-8.

44. Renz H, Smith HR, Henson JE, Ray BS, Irbin CG, Gelfand EW. Aerosolized antigen exposure without adjuvant causes increased IgE production and increased airway responsiveness in the mouse. $J$ Allergy Clin Immunol. 1992;89:1127-38.

45. Rossi RE, Monasterolo G. Prevalence of serum IgE antibodies to the Staphylococcal aureus enterotoxins (SAE, SEB, SEC, SED, TSST-1) in patients with persistent allergic rhinitis. Int Arch Allergy Immunol. 2004;133:261-6.

46. Sato E, Simpson KL, Grisham MB, Koyama S, Robbins RA. Effects of reactive oxygen and nitrogen metabolites on RANTES- and IL-5-induced eosinophil chemotactic activity in vitro. Am J Pathol. 1999;155:591-8.

47. Shahabuddin S, Ponath P, Schleimer RP. Migration of eosinophils across endothelial cell monolayers: interactions among II-5, endothelial-activating cytokines, and C-C chemokines. J Immunol. 2000;164:3847-54.

48. Tillie-Leblond I, Gosset $P$, Tonnel AB. Inflammatory events in severe acute asthma. Allergy. 2005;60:23-9. 
49. Vargaftig BB. What can we learn from murine models of asthma? Clin Exp Allergy. 1999;29 Suppl. 1:9-13, suplement 1

50. Wenzel SE, Schwartz LB, Langmack EL, Halliday JL, Trudeau JB, Gibbs RL, et al. Evidence that severe asthma can be divided pathologically into two inflammatory subtypes with distinct physiologic and clinical characteristics. Am J Respir Crit Care Med. 1999;160:1001-8.

51. Won SJ, Huang WT, Lai YS, Lin TM. Staphylococcal enterotoxin $A$ acts through nitric oxide synthase mechanisms in human peripheral blood mononuclear cells to stimulate synthesis of pyrogenic cytokines. Infect Immun. 2000;68:2003-8. 